\title{
Comparison and Validation of Selected Evapotranspiration Models for Conditions in Poland (Central Europe)
}

\author{
Pawel Bogawski • Ewa Bednorz
}

Received: 24 January 2014 / Accepted: 1 September 2014 /

Published online: 12 September 2014

(C) The Author(s) 2014. This article is published with open access at Springerlink.com

\begin{abstract}
The FAO-56 Penman-Monteith (PMF56) model is accepted as the standard method for estimating reference crop (grass) evapotranspiration. However, poor data availability limits the use of this method in many regions. This study aimed to overcome this limitation (1) by evaluating the goodness-of-fit of selected simple evapotranspiration methods in relation to the PMF56 model and (2) by adjusting four of these models and developing a multiple regression equation for conditions in Poland using the PMF56 model as a reference. Using daily meteorological data, four simple models were calibrated by the generalised reduced gradient (GRG) method; moreover, a multiple regression equation was developed on the basis of Cochrane-Orcutt estimation because the error term of the ordinary least squares model was autocorrelated. When radiation data were lacking and sunshine duration data were available, the PMF56 method with a calibrated Ångström-based estimation of solar radiation was the most accurate method (relative error, $R E=0.096$, for Sulejów). When neither radiation nor sunshine duration data were included in the dataset, the calibrated Penman method performed best $(R E=$ $0.254)$. Moreover, when only temperature or pan evaporation data were available, the calibrated Hargreaves method provided the most accurate results $(R E=0.275)$. Much poorer results were obtained using the calibrated pan coefficient method $(R E=0.435)$. Ultimately, we developed a multiple regression method in this study that exhibited good performance $(R E=0.170)$. Taking into account the data limitations, the methods calibrated in this study are recommended for estimating evapotranspiration in Central Europe. This approach would substantially decrease the errors produced by the recommended non-calibrated equations.
\end{abstract}

Keywords Evaporation · Penman-Monteith FAO-56 · optimisation · irrigation · Hargreaves

\footnotetext{
P. Bogawski $(\square)$

Faculty of Biology, Laboratory of Aeropalynology, Adam Mickiewicz University, Umultowska 89, 61-614 Poznan, Poland

e-mail: bogawski@amu.edu.pl

P. Bogawski $\cdot$ E. Bednorz

Faculty of Geographical and Geological Sciences, Department of Climatology, Adam Mickiewicz

University, Dziegielowa 27, 61-680 Poznan, Poland
} 


\section{Introduction}

Reliable estimates of evapotranspiration, which is defined as the process of simultaneous water evaporation from soil and transpiration from plants, are one of the most critical considerations for the efficient use of water resources, mainly in irrigation planning and management (e.g., Allen et al. 1998; Cristea et al. 2013). In Poland, irrigation has been shown to markedly increase the yields and quality of potatoes, sugar and red beat, radishes, strawberries, plums, apples and pears (Rolbiecki et al. 2003, 2004; Rzekanowski 2009; Żarski 2009). When irrigated, cultivated plants can better withstand the dry conditions that may occur in Central Europe during the growing season (Żarski 2009; Bonaccorso et al. 2013). Therefore, the area of irrigated lands in Poland is predicted to increase (Eabędzki 2007). However, one of the obstacles in applying irrigation is the small amount of water resources, which is $<1,500 \mathrm{~m}^{3}$ year $^{-1}$ per capita in Poland, while in Europe, water resources are 4,500 $\mathrm{m}^{3}$ year ${ }^{-1}$ per capita (Michalczyk and Sposób 2011). As a result, it is urgent to accurately estimate water losses (evapotranspiration) to more efficiently utilise water resources.

The first step in studying water losses from the land surface is to estimate the reference crop (grass) evapotranspiration $\left(E T_{0}\right)$ (Allen et al. 1998). The most accurate methods for this estimation use lysimeter measurements (Xu et al. 2013) or mathematical models, such as the Penman-Monteith equation and iterative methods (Widmoser 2009). However, lysimeter measurements are relatively difficult, expensive, and time consuming (Irmak et al. 2003). Therefore, the FAO (Food and Agriculture Organization of the United Nations) recommends an alternative method, i.e., the Penman-Monteith FAO-56 (PMF56), which was developed on the basis of lysimeter measurements in various regions around the world (Allen et al. 1998). Despite the errors that occur under certain unique conditions (Widmoser 2009), the PMF56 method is still considered the standard approach for calculating evapotranspiration for a reference surface (Xystrakis and Matzarakis 2011; Tabari et al. 2013), i.e., well-watered, actively growing grass of a height of $0.12 \mathrm{~m}$ that uniformly covers the area and has a surface resistance of $70 \mathrm{Sm}^{-2}$ and an albedo of 0.23 (Allen et al. 1998). The PMF56 method was used in this study as a reference method:

$$
E T_{0}=\frac{0.408\left(R_{n}-G\right)+\frac{900}{T_{a}+273} u\left(e_{s}-e_{a}\right)}{\Delta+\gamma(1+0.34 u)},
$$

where $E T_{0}$ is the reference crop evapotranspiration $\left[\mathrm{mm} \mathrm{day}^{-1}\right] ; R_{n}$ is the net radiation $\left[\mathrm{MJ} \mathrm{m}{ }^{-2}\right.$ day $\left.^{-1}\right] ; G$ is the soil heat flux $\left[\mathrm{MJ} \mathrm{m}^{-2}\right.$ day $^{-1}$, which is regarded as null for daily periods; $T_{a}$ is the average daily air temperature at a height of $2 \mathrm{~m}\left[{ }^{\circ} \mathrm{C}\right] ; u$ is the wind speed at a height of $2 \mathrm{~m}\left[\mathrm{~m} \mathrm{~s}^{-1}\right] ; e_{s}$ is the saturation vapour pressure $[\mathrm{kPa}] ; e_{a}$ is the actual vapour pressure $[\mathrm{kPa}] ; e_{s}-e_{a}$ is the vapour pressure deficit $[\mathrm{kPa}] ; \Delta$ is the slope of the saturation vapour pressure-temperature curve $\left[\mathrm{kPa}{ }^{\circ} \mathrm{C}^{-1}\right]$; and $\gamma$ is the psychrometric constant $\left[\mathrm{kPa}{ }^{\circ} \mathrm{C}^{-1}\right]$.

In many locations, the complete dataset of meteorological variables required for PMF56 calculations is not available. Therefore, simple empirical evapotranspiration models, using a lesser number of input variables (e.g., the Hargreaves, Penman or Thornthwaite methods), are frequently used instead (Sentelhas et al. 2010). However, the application of simple equations requires calibration to regional conditions because large biases can result from applying partially empirical formulae that have been calibrated for different regions (Xystrakis and Matzarakis 2011). Comprehensive studies evaluating such simplified evapotranspiration equations against the PMF56 
method have been conducted in different regions throughout the world, including the Netherlands, Syria, the USA, the Philippines and Spain (Stöckle et al. 2004), Bulgaria (Popova et al. 2006), Tunisia (Jabloun and Sahli 2008), Serbia (Trajkovic and Kolakovic 2009), Canada (Sentelhas et al. 2010), Southern Greece (Xystrakis and Matzarakis 2011) and Iran (Tabari et al. 2013).

In Poland, the problem of meteorological data availability also exists. The input variables for the PMF56 method are measured at only a few stations. Due to this data limitation, simpler models are typically used, such as the Penman and Hargreaves methods (Sarnacka et al. 1983; Treder et al. 2010). However, these methods have not been calibrated against the reference PMF56 method in Poland. Therefore, the main purposes of this work are (1) to evaluate the goodness-of-fit of the results from 11 simple evapotranspiration models in relation to the PMF56 model and (2) to adjust four of these models and develop a multiple regression equation for conditions in Poland using the PMF56 model as a reference. This approach ensures that the evapotranspiration values calculated using simple models will agree better with the values predicted by the PMF56 model and be more reliable.

\section{Materials and Methods}

\subsection{Study Area and Data}

Poland, which is located in Central Europe, lies at the border between two humid climate types, i.e., a snowy climate (Dfb) and a warm temperate climate $(\mathrm{Cfb})$, according to the updated Köppen climate classification system (Kottek et al. 2006). Three research stations were selected: Sulejów, Mikołajki and Piła (Fig. 1). The adjustment of the selected methods and the majority of the calculations were conducted using data from Sulejów (training dataset, 1981-2000). The remaining data from Sulejów (2001-2010) were used as a testing dataset and the data from two other stations, i.e., Mikołajki and Piła, served as validation data for the examined equations. The daily data from April to October were used in the analyses due to the possibility of snow cover during the period from November to March, which would result in markedly different evaporation conditions. The meteorological data series used in this study are described in Table 1. The wind speed data were obtained at $10 \mathrm{~m}$ and converted to the standard height of $2 \mathrm{~m}$ using a logarithmic wind speed profile for measurements above the reference surface. The actual and saturation vapour pressure, psychrometric constant and the slope of the saturation vapour pressure-temperature curve were derived according to recommendations provided by Allen et al. (1998).

\subsection{Evapotranspiration Estimation}

The commonly used methods for estimating evapotranspiration can be grouped into four categories based on the dataset type that is used: radiation, aerodynamic (masstransfer), temperature and pan evaporation (Xu and Singh 2002, Mallikarjuna et al. 2014). Twelve formulae (including the reference PMF56 method) derived from the literature and five formulae developed in this study for conditions in Poland were used. All formulae are cited and described in this section. The abbreviations for each method's name are given in brackets and then subsequently used in the paper. Variable abbreviations and their units are also described where they first appear; thereafter, the abbreviations are used. 


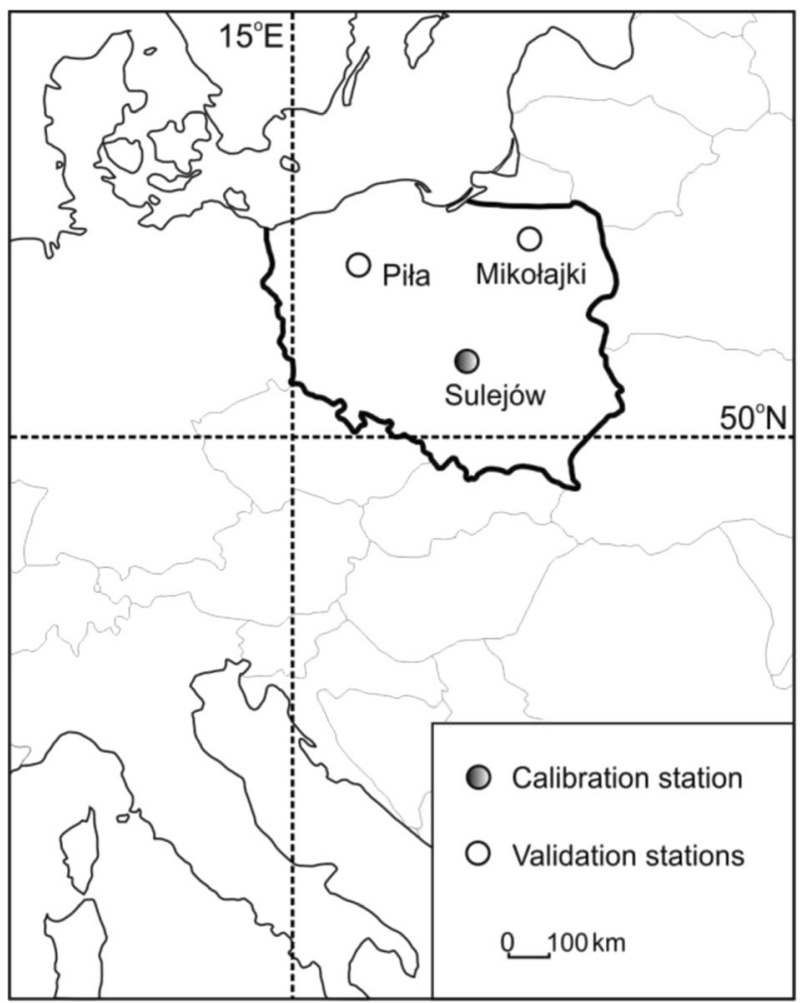

Fig. 1 Location of monitoring stations in Central Europe (boundaries of Poland in bold)

\subsubsection{Calibration Procedures}

Five selected equations were calibrated in this study. Four of these equations were derived from the literature (i.e., PMF_ANG, Penman, Hargreaves_FAO, and Pan coefficient_FAO) and subsequently optimised by changing the constants in the formulae (creating new formulations for Poland, i.e., PMF_ANG_adj, Penman_adj, Hargreaves_adj, Pan coefficient_adj). The optimisation was performed by applying the generalised reduced gradient method (Lasdon et al. 1973, 1976), which is available in the solver function in Microsoft Excel 2010. The solver add-in (http://www.solver.com for details) is a tool that can be used to fit equations by minimising the sum of the squared residuals. Multiple initial values were examined to ensure that the global minimum of the errors was found.

The fifth method developed in this study was a Cochrane-Orcutt multiple regression model (COMR) (for details, see the next subsection). $R_{n}, T_{\max }$ and $T_{\min }$ were used as independent variables, and PMF56 was used as a dependent variable. The estimated data series were then cross-validated by determining the evaluation indices that are presented in the next section.

\subsubsection{Radiation-Based Estimations}

Four radiation-based methods that are designed for humid climates were selected in this study. Two of them are largely similar to the PMF56 model (equation 1). The 
Table 1 Exact location, observation periods and meteorological data collected from weather stations Sulejów (training dataset: 1981-2000, testing dataset: 2001-2010), Mikołajki and Piła

\begin{tabular}{|c|c|c|c|c|c|c|}
\hline \multirow[t]{2}{*}{ Description } & \multirow[t]{2}{*}{ Abbreviation } & \multirow[t]{2}{*}{ Unit } & \multicolumn{4}{|l|}{ Station } \\
\hline & & & Sulejów & Sulejów & Mikołajki & Piła \\
\hline Latitude & - & decimal degrees & $51.35^{\circ} \mathrm{N}$ & $51.35^{\circ} \mathrm{N}$ & $53.78^{\circ} \mathrm{N}$ & $53.13^{\circ} \mathrm{N}$ \\
\hline Longitude & - & decimal degrees & $19.87^{\circ} \mathrm{E}$ & $19.87^{\circ} \mathrm{E}$ & $21.58^{\circ} \mathrm{E}$ & $16.75^{\circ} \mathrm{E}$ \\
\hline Altitude & - & $\mathrm{m}$ a.s.l. & 189 & 189 & 132 & 73 \\
\hline Observation periods & - & years & 1981-2000 & 2001-2010 & 2001-2010 & $2001-2010$ \\
\hline $\begin{array}{c}\text { Meteorological } \\
\text { parameters }\end{array}$ & & & Average values ${ }^{1}$ & & & \\
\hline Net radiation & $R_{n}$ & $\mathrm{MJ} \mathrm{m}^{-2}$ day $^{-1}$ & 6.8 & 7.3 & 6.9 & 7.1 \\
\hline Solar radiation & $R_{s}$ & $\mathrm{MJ} \mathrm{m}^{-2}$ day $^{-1}$ & 10.8 & 11.7 & 11.6 & 11.5 \\
\hline Sunshine duration & $n$ & hour & 6.1 & 6.8 & 7 & 6.9 \\
\hline Mean air temperature & $T_{a}$ & ${ }^{\circ} \mathrm{C}$ & 13.5 & 14.1 & 13.8 & 14.1 \\
\hline $\begin{array}{l}\text { Maximum air } \\
\text { temperature }\end{array}$ & $T_{\max }$ & ${ }^{\circ} \mathrm{C}$ & 19.0 & 19.9 & 18.5 & 19.7 \\
\hline $\begin{array}{l}\text { Minimum air } \\
\text { temperature }\end{array}$ & $T_{\min }$ & ${ }^{\circ} \mathrm{C}$ & 8.11 & 8.6 & 9.6 & 8.6 \\
\hline Precipitation totals & $P$ & $\mathrm{~mm}$ & 378.8 & 406.9 & 459.0 & 375.9 \\
\hline Relative humidity & $R H$ & $\%$ & 76.4 & 74.5 & 76.6 & 74.1 \\
\hline $\begin{array}{l}\text { Wind speed } \\
(2 \mathrm{~m} \text {; converted } \\
\text { from } 10 \mathrm{~m})\end{array}$ & $u$ & $\mathrm{~m} \mathrm{~s}^{-1}$ & 2.37 & 2.33 & 1.96 & 1.72 \\
\hline Pan evaporation & $E_{p a n}$ & $\mathrm{~mm}$ & - & 2.46 & - & 2.48 \\
\hline
\end{tabular}

1 Values averaged for the period April-October

only difference is in the net radiation component because these two methods were derived for situations when solar and net radiation data are lacking. These methods use sunshine duration as a proxy to calculate $R_{n}$ based on the Angström equation. The first method (PMF_ANG) uses procedures and default coefficients that were recommended by Allen et al. (1998) (equations 2-6):

$$
R_{n}=R_{n s}-R_{n l}
$$

where $R_{n s}$ is the net shortwave radiation $\left[\mathrm{MJ} \mathrm{m}^{-2}\right.$ day $^{-1}$ ] and $R_{n l}$ is the net longwave radiation $\left[\mathrm{MJ} \mathrm{m}^{-2}\right.$ day $\left.^{-1}\right]$. Here,

$$
R_{n s}=0.77 R_{s}
$$

where $R_{S}$ is the solar radiation [MJ m ${ }^{-2}$ day $^{-1}$ ], which can be defined as

$$
R_{s}=\left(a_{s}+b_{s} \frac{n}{N}\right) R_{a} .
$$

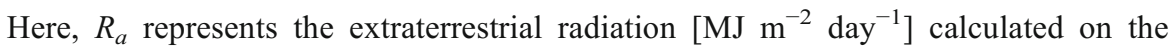
basis of procedure in Allen et al. (1998), $N$ is the maximum possible sunshine duration (hour), $n$ is the actual sunshine duration (hour), and $a_{s}$ and $b_{s}$ are regression constants. 
In the absence of locally calibrated values, Allen et al. (1998) recommended the following values: $a_{s}=0.25$ and $b_{s}=0.5$. Then, $R_{s}$ for clear-sky days $(n=N)$ can be computed as follows:

$$
R_{\text {sclear }}=0.75 R_{a} .
$$

Moreover, we can express $R_{n l}$ as follows based on the Stefan-Boltzmann law corrected for humidity and cloudiness:

$$
R_{n l}=\sigma\left[\frac{T_{\max , K}^{4}+T_{\min , K}^{4}}{2}\right]\left(0.34-0.14 \sqrt{e_{a}}\right)\left(1.35 \frac{\left(a_{s}+b_{s} \frac{n}{N}\right) R_{a}}{0.75 R_{a}}\right)-0.35
$$

where $\sigma$ is the Stefan-Boltzmann constant $\left[4.90310^{-9} \mathrm{MJ} \mathrm{K}^{-4} \mathrm{~m}^{-2}\right.$ day $\left.^{-1}\right], T_{\max , K}$ is the maximum absolute temperature during a $24-\mathrm{h}$ period $\left[\mathrm{K}={ }^{\circ} \mathrm{C}+273.16\right]$, and $T_{\min , K}$ is the minimum absolute temperature during a 24-h period $\left[\mathrm{K}={ }^{\circ} \mathrm{C}+273.16\right]$.

The second method (PMF_ANG_adj) is similar to the previous approach (PMF_ANG); however, the $R_{S}$ calculation was adjusted based on observational data by establishing a simple linear regression between the clearness index $\left(R_{s} / R_{a}\right)$ and relative sunshine duration $(n / N)$, which was similarly performed by Sabziparvar et al. (2013) for Iran. The constants were calibrated in this study using a large 20-year daily dataset from Sulejów. The resulting equation for calculating $R_{S}$ is as follows:

$$
R_{s}=\left(0.094+0.549 \frac{n}{N}\right) R_{a}
$$

The third model was originally described by Priestley and Taylor (1972) and was constructed for non-advection conditions. This model is a simplification of the PMF56 model (Priestley-Taylor):

$$
E T_{0}=a \frac{\Delta}{\Delta+y}\left(R_{n}-G\right) \frac{1}{\lambda} .
$$

where $\alpha$ is an empirical coefficient equivalent to 1.26 (dimensionless) and is the latent heat of vapourisation [ $\mathrm{MJ} \mathrm{kg}^{-1}$ ].

A multiple regression model was also used. The model was developed in this study for conditions in Poland. Initially, $R_{n}, T_{\max }$ and $T_{\min }$ were used as independent variables, and PMF56 was used as a dependent variable. $T_{\min }$ was an insignificant parameter of the ordinary least squares regression model; therefore, it was eliminated. However, the time series used to develop the linear regression model did not satisfy the best linear unbiased estimate (BLUE) condition (the residuals were serially correlated based on a Durbin-Watson test, $d w=1.342, p<0.001)$. In this case, we applied the Cochrane-Orcutt estimation method, which is commonly used to formulate more reliable models if the error term is autocorrelated. The use of the Cochrane-Orcutt model is common in econometrics; however, its use is rare outside this field (Wen 2009). More information regarding the use of this algorithm in climatology and hydrology can be found in Thejll and Schmith (2005) and Wen (2009). We present only the final model that satisfies the BLUE condition (the residuals exhibited no serial correlation according to a Durbin-Watson test, $d w=$ $2.019, p=0.660$ ). The collinearity did not affect the results of this regression method because the variance inflation factors $(V I F=1.694)$ were less than 5 (O'Brien 2007). The Cochrane-Orcutt multiple regression model determined in this study is as follows (COMR):

$$
E T_{0}=-0.755+0.257 R_{n}+0.062 T_{\max } .
$$




\subsubsection{Aerodynamic-Based Estimations}

Aerodynamic (mass-transfer) methods are based on Dalton's law, which describes the turbulent transfer of water vapour from an evaporating surface to the atmosphere (Singh and $\mathrm{Xu}$ 1997). These methods use simple forms and can be successfully applied when radiation or sunshine duration data are not available. Five of these methods were used in this study. The basic version of the Dalton (1802) equation (Dalton) is as follows:

$$
E T_{0}=(0.3648+0.07223 u)\left(e_{s}-e_{s}\right) .
$$

The WMO (1966) method, designed to calculate $E T_{0}$ on a global scale, was also selected (WMO):

$$
E T_{0}=(0.1298+0.0934 u)\left(e_{s}-e_{a}\right) .
$$

The other three models developed and applied for Central European conditions included the Mahringer (1970) model for Austria (Mahringer):

$$
E T_{0}=0.15072 \cdot \sqrt{3.6 u} \cdot\left(e_{s}-e_{a}\right),
$$

the Penman simplified method (1948) (Penman):

$$
E T_{0}=0.35(1+0.24 u)\left(e_{s}-e_{a}\right),
$$

and the Penman simplified method adjusted for conditions in Poland (Penman_adj):

$$
E T_{0}=0.36(1+0.14 u)\left(e_{s}-e_{a}\right) .
$$

\subsubsection{Temperature-Based Estimation}

Frequently, only one (air temperature) or two (air temperature and precipitation) fundamental meteorological variables are recorded at a station. In these cases, various forms of the Hargreaves equation (Hargreaves and Samani 1985) are recommended for calculating $E T_{0}$. This method can be easily applied by practitioners because it does not require a diverse data series. Five variants developed for different purposes or areas were used in this study. The first method, recommended by Allen et al. (1998), is designed for stations for which only temperature data are available (Hargreaves_FAO):

$$
E T_{0}=0.408 \cdot 0.0023\left(T_{a}+17.8\right)\left(T_{\max }-T_{\min }\right)^{0.5} \cdot R_{a}
$$

Two other versions of the model have been previously developed for $E T_{0}$ comparisons on a global scale (Droogers and Allen 2002) (Hargreaves_globe):

$$
E T_{0}=0.408 \cdot 0.0025\left(T_{a}+16.8\right)\left(T_{\max }-T_{\min }\right)^{0.5} \cdot R_{a},
$$

and one of these models was designed for stations for which air temperature and precipitation data are available (Hargreaves_precip):

$$
E T_{0}=0.408 \cdot 0.0013\left(T_{a}+17.0\right)\left(\left(T_{\max }-T_{\min }\right)-0.0123 P\right)^{0.5} \cdot R_{a},
$$

where $\mathrm{P}$ is the precipitation [mm].

Finally, previous studies have derived equations based on the Hargreaves formula (Hargreaves and Samani 1985) and modified them for European conditions. The first of these 
equations was derived by Trajkovic (2007) for Balkans (Hargreaves_Balk), while the second equation was developed in this study for Poland (Hargreaves_adj).

The Hargreaves_Balk model is defined as follows:

$$
E T_{0}=0.408 \cdot 0.0023\left(T_{a}+17.8\right)\left(T_{\max }-T_{\min }\right)^{0.424} \cdot R_{a} .
$$

Moreover, the Hargreaves_adj model is represented by the following relationship:

$$
E T_{0}=0.408 \cdot 0.001\left(T_{a}+17.0\right)\left(T_{\max }-T_{\min }\right)^{0.724} \cdot R_{a} .
$$

\subsubsection{Pan Evaporation-Based Estimation}

In Poland, deep sunken pans (surface area $=19.6 \mathrm{~m}^{2}$, depth=2 $\mathrm{m}$ ) are used at monitoring stations to measure evaporation from free surface water (available only from Sulejów and Piła). This variable can be used to estimate $E T_{0}$ when the $K_{p}$ coefficient is applied (Pan coefficient_FAO):

$$
E T_{0}=K_{p} \cdot E T_{p a n}
$$

where $K_{p}$ is the empirical pan coefficient and $E T_{\text {pan }}$ is the pan evaporation [mm].

Allen et al. (1998) determined $K_{p}$ for sunken pans in Colorado; this coefficient can be applied to sunken pans used in Poland $\left(K_{p}\right)$ :

$$
\begin{aligned}
& K_{p}= \\
& 0.87+0.119 \cdot \ln \underset{\sim}{\left\{F_{W}\right\}}(F E T)-0.0157[\ln (86.4 u)]^{2}-0.019 \cdot \ln \left(R H_{a}\right) \quad-
\end{aligned}
$$

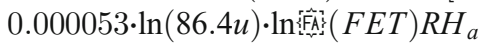

where $F E T$ is the distance from the evaporimeter to the surrounding low-growing vegetation [m] and $R H_{a}$ is the daily average air relative humidity [\%].

The next equation was used to calculate the pan coefficient for sunken pans adjusted for conditions in Poland $\left(K_{p_{-} a d j}\right)$ :

$$
\begin{aligned}
& K_{p \_a d j}=
\end{aligned}
$$

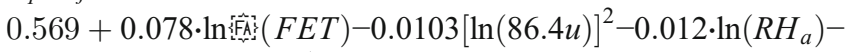

$$
\begin{aligned}
& 0.000035 \cdot \ln (86.4 u) \cdot \ln \underset{\sim}{[F A}\}(\text { FET }) R H_{a}
\end{aligned}
$$

$K_{p \_a d j}$ was applied in equation (20) to adjust for conditions in Poland (Pan coefficient_adj method).

\subsection{Statistical Analysis}

\subsubsection{Evaluation of Performance}

Five statistical measures were used to assess the reliability of the different methods compared to the reference PMF56 evapotranspiration dataset (at a daily basis).

The RMSE (root-mean-square error) is defined as

$$
R M S E=\sqrt{\frac{\sum_{i=1}^{n}\left(P_{i}-O_{i}\right)^{2}}{n}},
$$


where $P_{i}$ and $O_{i}$ are the estimated and reference data, respectively, at the $i^{\text {th }}$ data point and $n$ is the total number of data points.

Furthermore, the $R E$ (relative error) is defined as follows:

$$
R E=\frac{R M S E}{\bar{O}}
$$

where $\bar{O}$ is the mean value of the reference data.

The RMSEs are provided in millimetres, and the REs are dimensionless. The estimated data agree perfectly with the reference data when both the $R E$ and the RMSE are 0 .

The Willmott (1982) index of agreement can be defined as

$$
d=1-\frac{\sum_{i=1}^{n}\left(P_{i}-O_{i}\right)^{2}}{\sum_{i=n}^{n}\left(\left|P_{i}^{\prime}\right|+\left|O_{i}^{\prime}\right|\right)^{2}},
$$

where $P^{\prime}{ }_{i}=P-\bar{O}$ and $O^{\prime}{ }_{i}=O-\bar{O}$.

The index $d$ is dimensionless; perfect agreement between the reference and estimated data occurs when $d=1$. The coefficient of determination $\left(R^{2}\right)$ and the slope $(m)$ of the regression between the PMF56 data (assumed to be the observed data) and the other simple equations (assumed to be the predicted data) were also calculated.

These statistical indices were calculated and presented for the testing period at the three stations. In addition, three indices $\left(R E, R^{2}\right.$, and $d$ ) were calculated for 30 -days periods to determine the changes in the estimation accuracy for the different months of the testing period. Two examples of the aforementioned variability are presented in this paper for the original Hargreaves_FAO and calibrated Hargreaves_adj models.

\subsubsection{Differences in Monthly and Annual Evapotranspiration}

Monthly and annual evapotranspiration were calculated using the original and calibrated equations. Analysis of variance (ANOVA) and Tukey's post-hoc tests were then used to determine the differences between the reference PMF56 model and the other models used in this study and to assess the applicability of the simplified models.

\section{Results}

\subsection{Warm Season (April-October) Evapotranspiration}

Sixteen methods were tested against the reference evapotranspiration data calculated using the PMF56 model. These analyses revealed that seven methods produced warm season $E T_{0}$ totals that were significantly different from the reference series (ANOVA: $F=139.1, p<0.001$, and $d f=16$ ). The results of the remaining methods (i.e., the PMF_ANG_adj, Priestley-Taylor, COMR, Penman, Penman_adj, Dalton, Hargreaves_adj, Pan coefficient_FAO and Pan coefficient_adj methods) were consistent with the PMF56 data. In general, the best estimations were obtained using the radiation-based methods, followed by the mass-transfer-based, pan coefficient-based and temperature-based methods (Fig. 2). For example, the mean $E T_{0}$ in April-October calculated using the COMR method was very similar to that calculated using the PMF56 model (478.4 mm and $483.7 \mathrm{~mm}$, respectively); the extreme $E T_{0}$ values were best 


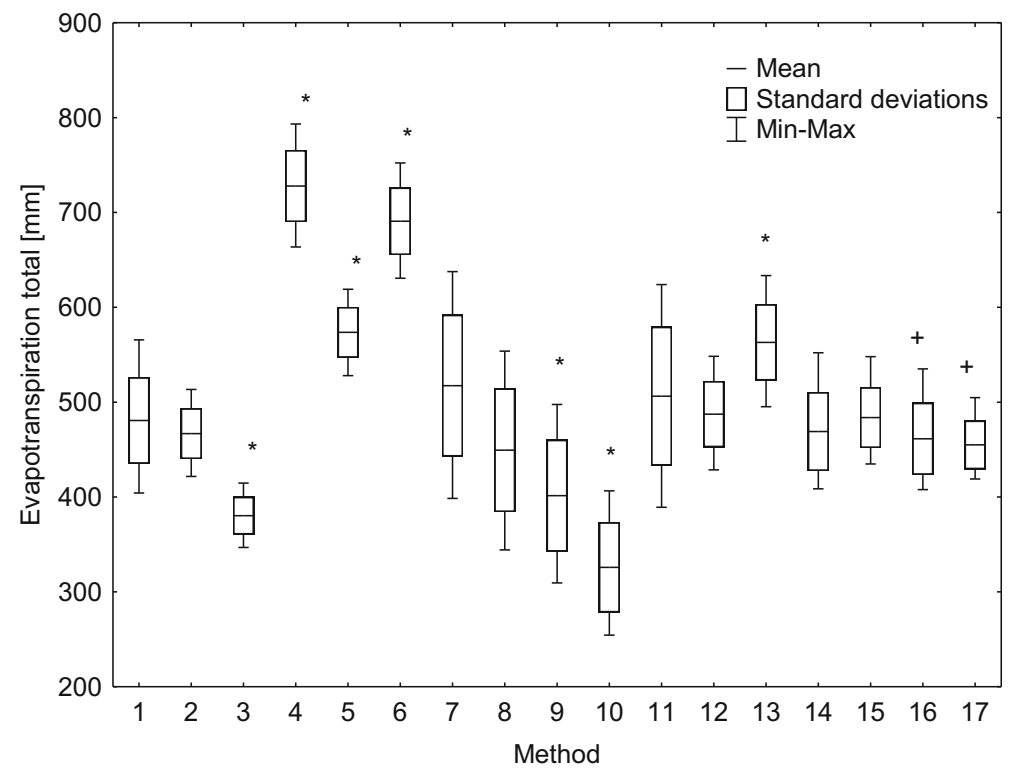

Fig. 2 Evapotranspiration totals for warm season (April-October) in Sulejów (1981-2010) calculated by 17 different methods (values differ from reference PMF56 evapotranspiration based on Tukey's post-hoc test, *p-value $<0.001$; + data for shorter period (May-October; 1999-2010)): 1 - PMF56, 2 - Hargreaves_adj, 3 - Hargreaves_precip, 4 Hargreaves_globe, 5 - Hargreaves_Balk, 6 - Hargreaves_FAO, 7 - Penman, 8 - Penman_adj, 9 - Mahringer, 10 WMO, 11 - Dalton, 12 - PMF_ANG adj, 13 - PMF ANG, 14 - Priestley-Taylor, 15 - COMR, 16 - Pan coefficient_FAO, 17 - Pan coefficient_adj

estimated by the other methods. The minimum and maximum annual $E T_{0}$ values were best predicted by the Priestley-Taylor equation $(\mathrm{min}=408.7 \mathrm{~mm}$ vs. $404.3 \mathrm{~mm}$ for the PMF56 model; max $=565.8 \mathrm{~mm}$ vs. $552.1 \mathrm{~mm}$ for the PMF56 model). The largest discrepancies were produced by the Hargreaves_precip and WMO methods, which underestimated $E T_{0}$, as well as the Hargreaves_globe and Hargreaves_FAO models, which overestimated $E T_{0}$ relative to the PMF56 results.

\subsection{Monthly Evapotranspiration Estimation}

Three methods correctly predicted $E T_{0}$ in all months (Table 2): PMF_ANG_adj, COMR and Hargreaves_adj. The remaining methods overestimated or underestimated $E T_{0}$ for at least 1 month. For example, PMF_ANG significantly overestimated the reference value during the period April-August.

The Dalton method performed best among the selected aerodynamic methods (5 months were correctly predicted); however, this method overestimated $E T_{0}$ in August and October relative to the PMF56 results. In addition, both Penman methods performed well (4 months were correctly predicted). The Mahringer and WMO methods significantly underestimated $E T_{0}$ compared to the reference value in 4 and 6 months, respectively.

The pan coefficient methods accurately estimated the monthly $E T_{0}$ during the summer months (June-August), whereas they underestimated and overestimated $E T_{0}$ before and after this period, respectively, compared to the reference values. 
Table 2 Average monthly evapotranspiration totals obtained by various simplified methods at Sulejów station in years 1981-2010

\begin{tabular}{|c|c|c|c|c|c|c|c|}
\hline \multirow[t]{2}{*}{ Methods } & \multicolumn{7}{|c|}{ Monthly evapotranspiration [mm] } \\
\hline & April & May & June & July & August & September & October \\
\hline \multicolumn{8}{|l|}{ Reference method: } \\
\hline PMF56 & 54.8 & 83.9 & 89.9 & 98.3 & 81.6 & 46.7 & 25.6 \\
\hline \multicolumn{8}{|l|}{ Radiation based methods: } \\
\hline PMF_ANG & $63.8 * *$ & $97.1 * *$ & $105.0 * *$ & $115.6^{*}$ & $96.6 * *$ & 54.6 & 30.3 \\
\hline PMF_ANG_adj & 56.0 & 83.0 & 87.4 & 97.3 & 85.9 & 48.1 & 29.7 \\
\hline Priestley-Taylor & 47.8 & 85.4 & 96.3 & 102.8 & 79.9 & 41.8 & $15.0 * *$ \\
\hline COMR & 51.3 & 84.0 & 90.6 & 98.3 & 85.7 & 47.7 & 20.8 \\
\hline \multicolumn{8}{|c|}{ Mass transfer based methods: } \\
\hline Dalton & 57.2 & 79.0 & 81.2 & 101.4 & $95.7 * *$ & 55.2 & $36.6 * *$ \\
\hline Mahringer & $46.2 *$ & $62.8 * *$ & $64.3 * *$ & $79.6^{*}$ & 74.8 & 43.9 & 29.9 \\
\hline WMO & $38.0 * *$ & $50.8 * *$ & $52.0 * *$ & $63.8 * *$ & $60.1 * *$ & $36.1^{*}$ & 25.1 \\
\hline Penman & 58.7 & 80.8 & 82.9 & 103.3 & $97.5^{* *}$ & $56.5^{*}$ & $37.7 * *$ \\
\hline Penman_adj & 50.5 & $70.2 * *$ & $72.1 * *$ & 90.4 & 85.4 & 48.8 & $32.0 * *$ \\
\hline \multicolumn{8}{|c|}{ Temperature based methods: } \\
\hline Hargreaves_FAO & $75.2^{* *}$ & $119.1^{* *}$ & $131.8 * *$ & $144.0 * *$ & $117.2 * *$ & $68.2 * *$ & $35.3^{* *}$ \\
\hline Hargreaves_precip & $41.2 * *$ & $65.5 * *$ & $72.7 * *$ & $79.5^{*}$ & $64.7 * *$ & 37.5 & $19.3^{* *}$ \\
\hline Hargreaves_globe & $78.6^{* *}$ & $125.3^{* *}$ & $139.1 * *$ & $152.2 * *$ & $123.9 * *$ & $71.8^{* *}$ & $36.9 * *$ \\
\hline Hargreaves_Balk & $62.5^{*}$ & $98.6 * *$ & $109.5^{* *}$ & $119.1 * *$ & $96.9 * *$ & $57.1 * *$ & 29.9 \\
\hline Hargreaves_adj & 49.6 & 80.4 & 89.4 & 98.6 & 80.2 & 45.6 & 22.9 \\
\hline \multicolumn{8}{|c|}{ Pan evaporation based methods ${ }^{1}$ : } \\
\hline Pan coefficient_FAO & - & $60.7 * *$ & 93.7 & 103.7 & 97.1 & $71.2 * *$ & $35.1 * *$ \\
\hline Pan coefficient_adj & - & $64.7 * *$ & 87.2 & 93.9 & 89.4 & $72.0 * *$ & $47.7 * *$ \\
\hline
\end{tabular}

Monthly values differ significantly (based on Tukey's post-hoc test) from the PMF56 method at

$* p$-value $<0.05$

$* * p$-value $<0.01$

${ }^{1}$ Mean monthly values for shorter period (1999-2010)

In general, the Hargreaves methods produced the least accurate monthly $E T_{0}$ estimates. Only the Hargreaves_adj method performed well, whereas the results of the other methods differed significantly from the PMF56 data.

\subsection{Daily Evapotranspiration Estimation}

The daily evapotranspiration estimates produced using the 16 simplified methods were compared against the PMF56 evapotranspiration data. The best estimates were obtained using the radiation methods (Table 3). The PMF_ANG_adj, Priestley-Taylor and COMR methods resulted in the lowest relative error $(R E<0.18)$, a high determination coefficient $\left(R^{2}>0.9\right)$, a high Willmott index of agreement $(d>0.97)$ and a slope of the regression close to $1(0.908<m$ $<1.089$ ) for all stations. Slightly worse results were obtained using the standard, FAOrecommended PMF_ANG method. 


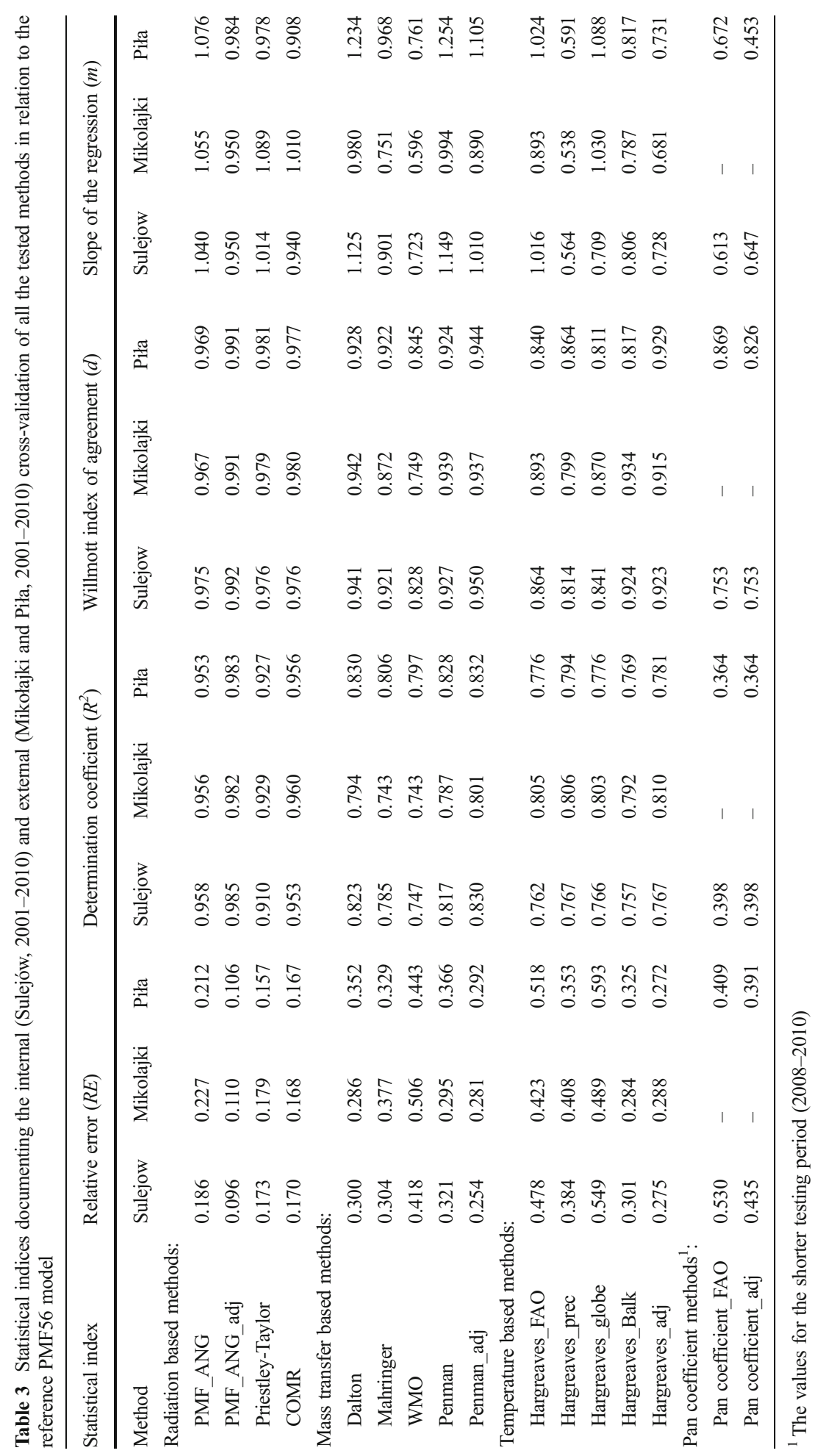


The Dalton, Penman adj and Penman methods were the most accurate among the aerodynamic methods $\left(R E<0 . \overline{3} 7, R^{2}>0.78\right.$, and $\left.d>9.2\right)$. However, their regression slopes exhibited large variations between stations (e.g., Penman: for Mikołajki, $m=0.994$, and for Piła, $m=$ 1.254). The Mahringer and WMO methods performed poorly $\left(R E>0.4, R^{2}<0.8\right.$, and $\left.d<0.85\right)$.

The various Hargreaves methods produced inconsistent results. The unadjusted FAO method (Hargreaves_FAO), which is considered the standard method in situations where data are scarce, produced unsatisfactory results $(R E>0.5$ and $d<0.9)$. This model performed much better $(R E<$ 0.29 and $d>0.91)$ after being optimised for conditions in Poland (Hargreaves_adj). The most significant errors were obtained using the Hargreaves_globe method $(R E \approx 0.6$ in Piła).

The results of the pan coefficient methods were the most inconsistent with respect to the PMF56 data. Although the Pan coefficient_adj method produced a smaller $R E$ than the Hargreaves_FAO model, the correlation of the pan coefficient results with the PMF56 data was very poor $\left(R^{2}<0.4\right)$. For both pan coefficient methods, the regression slope was also low $(m<0.68)$.

\subsection{Optimisation Results}

Four commonly used evapotranspiration estimation methods were markedly improved for conditions in Poland (Table 3). The Hargreaves method yielded the greatest reduction in the error. For example, the $R E$ decreased from 0.478 to 0.275 for the testing period. The Willmott index of agreement was also greatly improved (0.781 to 0.918). PMF_ANG was also corrected, i.e., the $R E$ decreased from 0.186 to 0.096 in Sulejów. The improvements in the Penman_adj (the $R E$ decreased from 0.321 to 0.254 ) and Pan coefficient_adj methods were relatively small.

The relative error and Willmott index of agreement were greatly improved upon optimisation, whereas the coefficient of determination and the slope of the regression changed to a lesser extent (Fig. 3). The changes in these indices during the testing period are presented as an example of the Hargreaves equation optimisation. The Hargreaves_adj model produced markedly lower relative errors and a higher Willmott index compared to the original Hargreaves_FAO method. However, at the beginning and end of the testing period, the optimisation yields were higher than in the middle of the testing period.

\section{Discussion}

\subsection{Evapotranspiration at Different Time Scales}

Nine methods did not show differences in evapotranspiration compared to the PMF56 results during the period April-October. However, only three of these methods were consistent with the reference method on a monthly basis (the PMF_ANG_adj, COMR and Hargreaves_adj models). The remaining methods incorrectly predicted at least one monthly $E T_{0}$ total during the warm season. The Priestley-Taylor (October), Penman_adj (May and June) and Pan coefficient (May) methods underestimated the monthly evaporation. Conversely, the Penman method overestimated the reference values for August, September and October; the Penman_adj and Dalton methods overestimated for October; and the pan coefficient methods overestimated for September and October.

The three best methods with respect to the annual and monthly time scales (the PMF_ANG_adj, COMR and Hargreaves_adj models) also performed well for a daily time scale. Two of these models are radiation-based methods; solar radiation is considered the most 

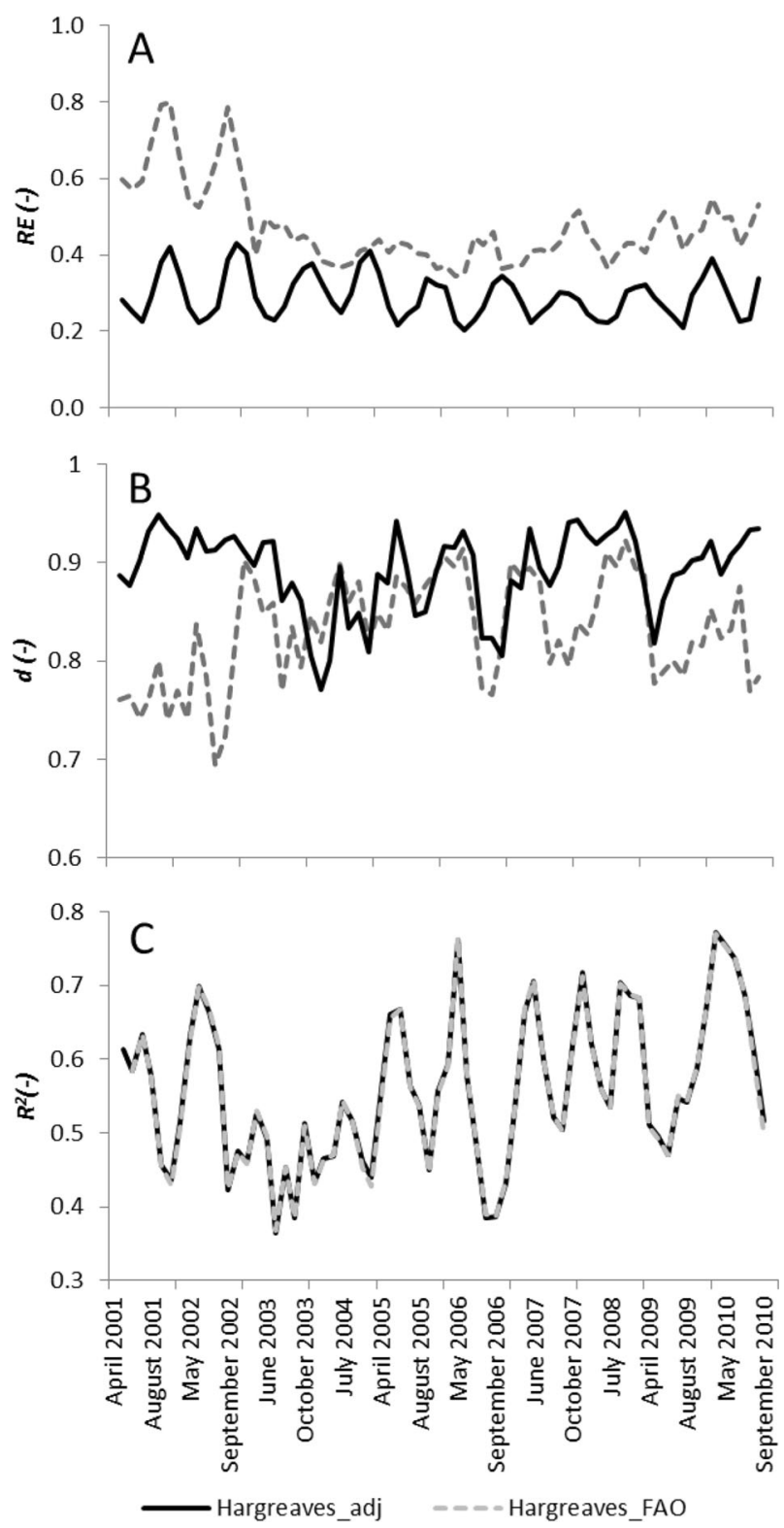

Fig 3 3-months moving average of monthly relative error (A), Willmott index of agreement (B) and determination coefficient $(\mathrm{C})$ for two forms of Hargreaves equation: Hargreaves_FAO and Hargreaves_adj in Sulejów

important factor influencing variations in evapotranspiration (Xu et al. 2006; Yin et al. 2008). Therefore, we decided to develop a multiple regression method for conditions in Poland (COMR). This method was developed using only temperature and radiation data. Tabari et al. (2013) found that such a radiation-based multiple regression equation was the optimal method in the humid climate of northern Iran because it resulted in a very small RMSE $\left(0.18 \mathrm{~mm} \mathrm{~d}^{-1}\right)$. However, the present study found that one method, i.e., the PMF_ANG_adj model, performed better at the daily time scale than the COMR method. 
When solar radiation or sunshine duration data were lacking, the best performance at the daily time scale was obtained by the Penman_adj method using water vapour deficit and wind speed data $\left(R E=0.254 \mathrm{~mm}, R^{2}=0.830, d=0.950\right.$, and $\left.m=1.01\right)$. The Dalton and Penman methods were also accurate without calibration $\left(R E=0.300-0.321, R^{2}=0.817-0.823, d=\right.$ $0.927-941$, and $m=1.125-1.149)$, indicating that the combination of vapour pressure deficit and wind speed data provides a good description of the evapotranspiration process.

If air temperatures measured at the station are the only available data, various studies have recommended the use of a Hargreaves equation to calculate $E T_{0}$ (Allen et al. 1998; Sentelhas et al. 2010). This method is particularly recommended when the data quality is expected to be low because this approach is less susceptible to errors in the dataset (Droogers and Allen 2002). However, the present study demonstrates that this method can produce large biases when it is not calibrated. The original Hargreaves_FAO method exhibited differences in the average seasonal values and in all monthly values when compared to the PMF56 data at Sulejów. At the daily time scale, this method produced the following parameters: $R E=0.478$, $R^{2}=0.762, d=0.864$ and $m=1.016$. With the exception of the regression slope, these results were poor. The Hargreaves_globe model performed even worse than the original version $(R E=$ $0.549)$. The inclusion of precipitation data in the Hargreaves equation led to a decrease in the $R E(0.384$ in Sulejów), whereas the regression slope decreased $(m=0.564)$, indicating an underestimation of the daily $E T_{0}$ values. However, after calibration to local conditions, the Hargreaves method resulted in errors similar to those of the aerodynamic methods, which require more data (Hargreaves_adj: $R E=0.275, R^{2}=0.767, d=0.923$, and $m=0.728$ ). This result is in agreement with other studies showing that the $R M S E$ is markedly decreased after calibration (e.g., from 1.103 to 0.703 in Sentelhas et al. 2010). This finding also confirms that the regional calibration of temperature-based methods is necessary to widely apply them in particular regions (Valipour 2014).

The pan coefficient methods provided a highly accurate prediction of the monthly $E T_{0}$ totals in summer (June-August). However, these methods underestimated $E T_{0}$ in the spring months and overestimated $E T_{0}$ in the autumn months relative to the PMF56 results. This is likely due to the use of large-volume sunken evaporation pans in Poland. As opposed to the Class A pan that is able to reliably predict $E T_{0}$ relative to the daily PMF56 data (Cobaner 2013; Tabari et al. 2013), a sunken tank requires more time to heat its contents from month to month and from day to day, which is one of the primary reasons for the low determination coefficient obtained for pan evaporation-based methods when plotted against the PMF56 data $\left(R^{2}=0.398\right)$.

\subsection{Performance of the Evapotranspiration Estimation Methods Within Poland}

Four equations of the 11 methods investigated in this study were calibrated to conditions in Poland (the PMF_ANG_adj, Penman_adj, Hargreaves_adj, and Pan coefficient_adj methods); one method was developed using a multiple regression procedure (COMR). Because these methods can yield different results for different locations, we assessed their performance for two other stations. The first validation station is located in western Poland (Piła); the second station, which is located in the northeastern part of the country (Mikołajki), was used to represent colder conditions. The statistical indices used to compare the different methods relative to the PMF56 model revealed small differences between these stations and the calibration station. For the PMF_ANG_adj model, the $R E$ varied between 0.096 and 0.110 , the $R^{2}$ varied between 0.982 and $0.98 \overline{5}$, and the $d$ and $\mathrm{m}$ values exhibited a slightly better accuracy at Piła and Mikołajki than at Sulejów, for which PMF_ANG_adj was originally calibrated. These differences are negligible and confirm that the adjustment of the method to 
conditions in Poland/Central Europe, was accurate. Similar small differences have been reported for other locations, e.g., Bulgaria (Popova et al. 2006).

The Penman_adj and Hargreaves_adj methods exhibited a similar performance for the validation stations. In several cases, the statistical indices suggested that the predictions were more accurate than for the calibration station, demonstrating that the equations obtained for Sulejów can be applied to other areas of the Polish lowlands.

The optimised pan coefficient $\left(K_{p}\right)$ method was the least efficient method regarding the validation stations, which may have been due to the relatively short data series used to optimise the standard equation. However, the 9 years of daily data used in this study are markedly more extensive than the dataset used by Stöckle et al. (2004) to successfully optimise $E T_{0}$ calculations. It is possible that the large size of the evaporation pans used in Poland could attribute to the poor performance of this method for the validation stations.

\section{Conclusions}

Several simple formulae were assessed for their potential to estimate reference crop evapotranspiration. Typically, accuracy decreases with decreasing data availability. When radiation data are unavailable and sunshine duration data are available, the PMF_ANG_adj method calibrated in this study is the best method for predicting $E T_{0}$. When sunshine radiation data are also not available, the simple Penman_adj method, using vapour pressure deficit and wind speed data, is recommended. When only temperature data are available, the Hargreaves_adj method (as calibrated in this study) is strongly recommended for use in Poland, Central Europe. This method markedly diminished the errors produced by the original Hargreaves_FAO equation. The accuracy of the three aforementioned methods did not vary among the calibration and validation stations.

Pan evaporation methods are not highly applicable in Poland. The standard Class A pan, which is used to obtain data for calculating $E T_{0}$, is not routinely used in Poland. Instead, large, 2-m-deep pans are used; these pans are less susceptible to changes in weather parameters. Therefore, these pans react to such variations more slowly.

Acknowledgments This work was funded by the Polish National Science Centre within the framework of project no. 2011/01/N/ST10/05954. We thank the Institute of Meteorology and Water Management for providing meteorological data. We also thank two anonymous reviewers for the constructive comments that greatly improved the manuscript.

Open Access This article is distributed under the terms of the Creative Commons Attribution License which permits any use, distribution, and reproduction in any medium, provided the original author(s) and the source are credited.

\section{References}

Allen RG, Pereira LS, Raes D, Smith M (1998) Crop evapotranspiration. Guidelines for computing crop water requirements. FAO Irrigation and Drainage. Paper no. 56. FAO, Rome

Bonaccorso B, Peres DJ, Cancelliere A, Rossi G (2013) Large scale probabilistic drought characterization over Europe. Water Resour Manag 27:1675-1692

Cobaner M (2013) Reference evapotranspiration based on class a pan evaporation via wavelet regression technique. Irrig Sci 31:119-134 
Cristea NC, Kampf SK, Burges SJ (2013) Linear models for estimating annual and growing season reference evapotranspiration using averages of weather variables. Int J Climatol 33:376-387

Dalton J (1802) Experimental essays on the constitution of mixed gases; on the force of steam of vapour from waters and other liquids in different temperatures, both in a torricellian vacuum and in air on evaporation and on the expansion of gases by heat. Mem Manch Lit Philos Soc 5:535-602

Droogers P, Allen RG (2002) Estimating reference evapotranspiration under inaccurate data conditions. Irrig Drain Syst 16:33-45

Hargreaves GL, Samani ZA (1985) Reference crop evapotranspiration from temperature. Appl Eng Agric 1(2): 96-99

Irmak S, Irmak A, Allen RG, Jones JW (2003) Solar and net radiation-based equations to estimate reference evapotranspiration in humid climates. J Irrig Drain Eng ASCE 129(5):336-347

Jabloun M, Sahli A (2008) Evaluation of FAO-56 methodology for estimating reference evapotranspiration using limited climatic data: applications to Tunisia. Agric Water Manag 95:707-715

Kottek M, Grieser J, Beck C, Rudolf B, Rubel F (2006) World Map of the Köppen-Geiger climate classification updated. Meteorol Z 15:259-263. doi:10.1127/0941-2948/2006/0130

Łabędzki L (2007) Irrigation in Poland - current status after reforms in agriculture and future development. J Water Land Dev 11:3-16. doi:10.2478/v10025-008-0001-6

Lasdon LS, Fox RL, Ratner MW (1973) Nonlinear optimization using the generalized reduced gradient method. Technical memorandum no. 325. Case Western Reserve University, Springfield

Lasdon LS, Waren AD, Jain A, Ratner M (1976) Design and testing of a generalized reduced gradient code for nonlinear programming. Technical Report 76-3. System Optimization Laboratory, Department of Operation Research, Stanford University, California

Mallikarjuna P, Aruna Jyothy S, Srinivasa Murthy D, Chandrasekhar Reddy K (2014) Performance of Recalibrated Equations for the Estimation of Daily Reference Evapotranspiration. Water Resour Manage. doi:10.1007/s11269-014-0733-9

Mahringer W (1970) Verdunstungsstudien am neusiedler See. Arch Met Geoph Biokl Ser B 18:1-20

Michalczyk Z, Sposób J (2011) Water resources of Poland and their state in Lublin district. Teka Kom Ochr Kszt Środ Przyr - OL PAN 8:104-111

O’Brien RM (2007) A caution regarding rules of thumb for variance inflation factors. Qual Quant 41:673-690

Penman HC (1948) Natural evaporation from open water, bare soil and grass. Proc R Soc Lond Ser A 193:120-145

Popova Z, Kercheva M, Pereira LS (2006) Validation of the FAO methodology for computing ETo with missing climatic data application to South Bulgaria. Irrig Drain 55:201-215

Priestley CHB, Taylor RJ (1972) On the assessment of surface heat flux and evapotranspiration using large scale parameters. Mon Weather Rev 100:81-92

Rolbiecki S, Rolbiecki R, Rzekanowski C, Żarski J (2003) Drip irrigation system as a factor for drought mitigation in vegetable growing on sandy soils in the region of Bydgoszcz. Acta Scientarum Polonorum Hortorum Cultus 2(2):75-84

Rolbiecki S, Wojdyła T, Rzekanowski C, Rolbiecki R, Grzelak B (2004) The influence of sprinkler irrigation and nitrogen dose on the yield, chemical composition as well as the storage value of Mors potato tubers. Ann Univ Mariae Curie-Skłodowska Lublin - Polonia, Sectio E LIX(3):1389-1395

Rzekanowski C (2009) Shaping of irrigation needs for fruit plants in Poland. Infrastruct Ecol Rural Areas 3:1927 (in Polish with English summary)

Sabziparvar AA, Mousavi R, Marofi S, Ebrahimipak NA, Heidari M (2013) An improved estimation of the angstrom-Prescott radiation coefficients for the FAO56 Penman-Monteith evapotranspiration method. Water Resour Manag 27:2839-2854

Sarnacka S, Brzeska J, Świerczyńska H (1983) Wybrane metody wyznaczania ewapotranspiracji potencjalnej. Materiały Badawcze, Warszawa: IMGW (in Polish)

Sentelhas PC, Gillespie TJ, Santos EA (2010) Evaluation of FAO Penman-Monteith and alternative methods for estimating reference evapotranspiration with missing data in southern Ontario, Canada. Agric Water Manag 97:635-644

Singh VP, Xu C-Y (1997) Evaluation and generalization of 13 mass-transfer equations for determining free water evaporation. Hydrol Process 11:311-323

Stöckle CO, Kjelgaard J, Bellocchi G (2004) Evaluation of estimated weather data for calculating PenmanMonteith reference crop evapotranspiration. Irrig Sci 23:39-46

Tabari H, Grismer ME, Trajkovic S (2013) Comparative analysis of 31 reference evapotranspiration methods under humid conditions. Irrig Sci 31:107-117

Thejll P, Schmith T (2005) Limitations on regression analysis due to serially correlated residuals: Application to climate reconstruction from proxies. J Geophys Res 110, D18103. doi:10.1029/ 2005JD005895

Trajkovic S (2007) Hargreaves versus Penman-Monteith under humid conditions. J Irrig Drain Eng 133(1):38-42 
Trajkovic S, Kolakovic S (2009) Evaluation of reference evapotranspiration equations under humid conditions. Water Resour Manag 23:3057-3067

Treder W, Wójcik K, Żarski J (2010) Preliminary assessment of the possibility of estimating water requirements of plants on the basis of simple meteorological measurements. Zeszyty Naukowe Instytutu Sadownictwa I Kwiaciarstwa im S Pieniążka 18:143-153 (in Polish with English summary)

Valipour M (2014) Use of average data of 181 synoptic stations for estimation of reference crop evapotranspiration by temperature-based methods. Water Resour Manage 28:4237-4255

Wen L (2009) Reconstruction natural flow in a regulated system, the Murrumbidgee River, Australia, using time series analysis. J Hydrol 364:216-226

Widmoser P (2009) A discussion on an alternative to Penman-Monteith equation. Agric Water Manag 96:711-721

Willmott CJ (1982) Some comments on the evaluation of model performance. Bull Am Meteorol Soc 63:1309-1313

WMO (1966) Measurement and estimation of evaporation and evapotranspiration. Tech. Pap. (CIMORep) 83. Geneva

Xu C-Y, Singh VP (2002) Cross comparison of empirical equations for calculating potential evapotranspiration with data from Switzerland. Water Resour Manag 16:197-219

Xu C-Y, Gong L, Jiang T, Chen D, Singh VP (2006) Analysis of spatial distribution and temporal trend of reference evapotranspiration and pan evaporation in Changjiang (Yangtze River) catchment. J Hydrol 327: 81-93

Xu J, Peng S, Ding J, Wei Q, Yu Y (2013) Evaluation and calibration of simple methods for daily reference evapotranspiration estimation in humid East China. Arch Agron Soil Sci 59(6):845-858

Xystrakis F, Matzarakis A (2011) Evaluation of 13 empirical reference potential evapotranspiration equations on the island of Crete in southern Greece. J Irrig Drain E-ASCE 137(4):211-222

Yin Y, Wu S, Zheng D, Yang Q (2008) Radiation calibration of FAO56 Penman-Monteith model to estimate reference crop evapotranspiration in China. Agric Water Manag 95:77-84

Żarski J (2009) Effects of cereal plants irrigation in Poland. Infrastruct Ecol Rural Areas 3:29-42 (in Polish with English summary) 